\title{
Erratum to: Avian diversity in a temperate tree-based intercropping system from inception to now
}

\author{
Sophie Gibbs • Hanita Koblents • \\ Brent Coleman - Andrew Gordon • \\ Naresh Thevathasan $\cdot$ Peter Williams
}

Published online: 14 March 2016

(C) Springer Science+Business Media Dordrecht 2016

\section{Erratum to: Agroforest Syst DOI 10.1007/s10457-016-9901-7}

In the original publication of the article, the last name of the author Williams was spelled incorrectly. The correct author name is given in this erratum.

The online version of the original article can be found under doi:10.1007/s10457-016-9901-7.

S. Gibbs · B. Coleman · A. Gordon $(\bowtie)$.

N. Thevathasan

School of Environmental Sciences, University of Guelph,

Guelph, ON N1G 2W1, Canada

e-mail: agordon@uoguelph.ca

B. Coleman

e-mail: colemanb@uoguelph.ca

H. Koblents

City of Halifax, Halifax, NS B3J 3A5, Canada

B. Coleman

Department of Geography, University of Toronto,

Toronto, ON M1C 1A4, Canada

P. Williams

Williams and Associates, Rockwood, ON NOB 2K0,

Canada 